\title{
STUDY OF GRAIN BOUNDARY OXIDATION OF HIGH ALLOYED CARBON STEELS AT COILING TEMPERATURE*
}

\author{
Larissa Agrizzi Ronqueti ${ }^{1}$ \\ Jérôme Favergeon ${ }^{2}$ \\ Marion Risbet ${ }^{3}$ \\ Michel Picard ${ }^{4}$
}

\begin{abstract}
The effect of coiling temperature on selective oxidation behaviour of binary and ternary iron-based model alloys containing different contents of Si or $\mathrm{Mn}$ were investigated by SEM and SIMS. The experiments were carried out with a temperature ranging from $450{ }^{\circ} \mathrm{C}$ to $700{ }^{\circ} \mathrm{C}$, under $\mathrm{N}_{2}-5 \% \mathrm{H}_{2}$ gas flow with a Dew Point of $-3.3^{\circ} \mathrm{C}$, for different durations. SEM images of binary iron-based model alloys revealed a decrease of grain boundary oxidation depth with increasing Silicon or Manganese content. At $530^{\circ} \mathrm{C}$ and $600^{\circ} \mathrm{C}$ SIMS results showed no Silicon diffusion toward surface, contrary to the results analyzed for $\mathrm{Fe}-\mathrm{x} \% \mathrm{Mn}$. Tests results and Wagner's theory application (specific cases $\mathrm{Fe}-0.2 \% \mathrm{Si}$ and $\mathrm{Fe}-0.5 \% \mathrm{Si}$ ) showed that grain boundary oxygen diffusion coefficient "Do ${ }_{G B}$ " is almost 60 to 70 times faster than oxygen bulk diffusion coefficient. These results helped to broaden knowledge of single-element effects on grain boundary oxidation, in addition, will contribute of the future works in new steels with complex alloy compositions.

Keywords: Intergranular oxidation; Selective oxidation; Thermogravimetry analysis; Cooling coils.
\end{abstract}

1 Master in Metallurgical Engineering, Ph.D. student / Research Engineer, Roberval Laboratory / Process Engineering, Sorbonne Universités - Université de Technologie de Compiègne / ArcelorMittal Global R\&D Maizières, Compiègne / Maizières-les-Metz, France.

2 Ph-D in Chemistry of Materials, Director of Roberval Laboratory, Roberval Mechanics Laboratory, Sorbonne Universités - Université de Technologie de Compiègne, Compiègne, France.

3 Ph-D in Mechanics of Materials, Associate Professor, Roberval Mechanics Laboratory, Sorbonne Universités - Université de Technologie de Compiègne, Compiègne, France.

4 Graduate in Energetic Sciences, Research Fellow, Process Engineering, ArcelorMittal Global R\&D Maizières, Maizières-les-Metz, France. 


\section{INTRODUCTION}

The oxide inclusions in the metal subsurface, particularly at grain boundaries, can be detrimental for the in-use properties of steel. Understanding the high temperature oxidation in steel is essential for being able to conceive lighter steel structures.

Due to increasing concerns about modern energy politics, environmental pollution and global warming, the European directive is requiring that automotive manufacturers reduce the average carbon dioxide emissions by 2020 . Thereby, the reduction of vehicle weight is considered to be the most promising way to enhance fuel economy in the future and consequently to decrease the carbon dioxide emissions. According to Bellhouse et al. [1], a 10\% reduction of vehicle weight can result in a 6 to $8 \%$ reduction in fuel consumption. Based on this idea, the steel industry is developing new high-strength steels (much higher alloy contents) in order to reduce the weight of the vehicle structure, without compromising its ductility, its formability and its crashworthy.

During the manufacturing of steel, it undergoes a series of high temperature processes in oxygen-rich atmospheres. As a result an iron oxide scale is formed on the strip surfaces. In the coils cooling step, the steel inner coil is not exposed to oxygen bearing atmosphere, but the wüstite-iron equilibrium releases a tiny amount of oxygen, which is sufficient to induce internal oxidation. It may proceed inside the grains (bulk oxidation) and along grain boundaries (grain boundary oxidation). Selective oxidation changes the steel mechanical properties, mainly due to grain boundary oxidation. The grain boundaries are considered short-paths for diffusion and this type of oxidation is strongly connected to the atomic structure of grain boundaries. The oxides present along the grain boundaries lead to a weakening of the cohesive strength of individual grains, causing severe embrittlement after forming procedures [2]. Thus, grain boundary oxidation is influenced mainly by coiling temperature, atomic structure of grain boundaries and diffusion reactions along grain boundaries [3, 4].

This paper focuses on the effect of coiling temperature and different contents of alloying elements in selective oxidation behavior. Binary and ternary iron-based model alloys containing different contents of Si or Mn were investigated by SEM and SIMS. Some results for selected Silicon contents could be interpreted through a Wagner's theory [5] of the diffusion within the grain boundary. The experiments were carried out with a temperature ranging from $450{ }^{\circ} \mathrm{C}$ to $700{ }^{\circ} \mathrm{C}$, under $\mathrm{N}_{2}-5 \% \mathrm{H}_{2}$ gas flow with a Dew Point of $-3.3^{\circ} \mathrm{C}$, for different durations (i.e. 2, 6, 16 and 26 hours).

\section{MATERIAL AND METHODS}

The iron-based model alloys were melted and hot rolled at the ArcelorMittal Maizières Global Research \& Development. The Table 1 below shows the chemical compositions of the model alloys.

Table 1. Chemical composition [wt. \%] of iron-based model alloys investigated.

\begin{tabular}{|c|cccc|}
\hline $\begin{array}{c}\text { Nominal } \\
\text { Composition }\end{array}$ & $\mathbf{S i}$ & Mn & C & Other elements \\
\hline $\mathrm{Fe}-0.2 \% \mathrm{Si}$ & 0.209 & 0.010 & 0.013 & \\
$\mathrm{Fe}-0.5 \% \mathrm{Si}$ & 0.496 & 0.003 & 0.012 & $<0.002$ \\
$\mathrm{Fe}-1.5 \% \mathrm{Si}$ & 1.58 & 0.001 & 0.002 & \\
\hline $\mathrm{Fe}-2 \% \mathrm{Mn}$ & 0.028 & 2.013 & 0.150 & $<0.002$ \\
$\mathrm{Fe}-5 \% \mathrm{Mn}$ & 0.0365 & 5.069 & 0.153 & $<0.002$ \\
\hline $\mathrm{Fe}-0.4 \% \mathrm{Si}-1 \% \mathrm{Mn}$ & 0.398 & 1.07 & 0.320 & \\
\hline
\end{tabular}


The samples used for the selective oxidation experiments were cut into square shaped pieces of $20 \mathrm{~mm} \times 14 \mathrm{~mm} \times 4 \mathrm{~mm}$ or $10 \mathrm{~mm} \times 10 \mathrm{~mm} \times 4 \mathrm{~mm}$. To obtain the clean sample surfaces and not covered by a rolled oxide layer, grinding was done with $\mathrm{SiC}$ grit paper (from 120 down to 4000 grit size) and followed by an electrolytic polishing. The electrolytic polishing was carried out during 15 minutes with $40 \mathrm{~V}$ and $199.9 \mathrm{~mA}$ in a solution composed by $950 \mathrm{ml}$ of ethylene glycol mono-butyl ether, 100 $\mathrm{ml}$ of methanol and $50 \mathrm{ml}$ of perchloric acid. This step was necessary to avoid the creation of new grains in sub-surface (recrystallization) due to the work-hardening induced by the mechanical polishing. Selective oxidation experiments were carried out using a SETARAM Thermobalance with a temperature ranging from $450{ }^{\circ} \mathrm{C}$ to $700{ }^{\circ} \mathrm{C}$, under $\mathrm{N}_{2}-5 \% \mathrm{H}_{2}$ with $150 \mathrm{ml} / \mathrm{min}$ of total gas flow and a Dew Point of $-3.3^{\circ} \mathrm{C}$, for different durations up to a maximum of 26 hours. In such conditions, the oxygen partial pressure in the atmosphere is high enough to oxidize alloying elements without oxidizing the iron.

After oxidation tests, cross sections of the samples were ground (120 down to 4000 grit) and polished with $3 \mu \mathrm{m}$ as well as $1 \mu \mathrm{m}$ diamond paste. The cross section observations and measurements of the grain boundary oxidation lengths were performed with a Field Emission Scanning Electron Microscopy (FE-SEM, LEO1550VP, Zeiss-Oxford Instruments) equipped with an Energy Dispersive Spectroscopy (EDS). The SEM images were obtained using the Backscattered Electrons Detector (BSD) with an incident electron beam accelerating potential of 20 $\mathrm{kV}$. To obtain depth profiles and mapping analysis, selected samples were examined using a CAMECA IMS 7F secondary ions mass spectrometry (SIMS). The operation conditions of SIMS were set by $5 \mathrm{kV} \mathrm{Cs+/+} \mathrm{and} 25 \mathrm{nA}$. The image depth profile conditions were field $250 \mu \mathrm{m} \times 250 \mu \mathrm{m}$ and each image was formed by accumulation on 20 sputtering cycle. The GDOES (Glow Discharge Optical Emission Spectroscopy - Horiba Jobin Yvon PROFILER 2) was also used to obtain information about carbon concentration profiles in some samples.

\section{RESULTS AND DISCUSSION}

\subsection{TG Analysis}

Very stable conditions for the thermobalance atmosphere furnace could be achieved. In the industrial situation, during cooling of coils, the oxygen partial pressure $\left(\mathrm{pO}_{2}\right)$ is set by the $\mathrm{Fe}-\mathrm{FeO}$ equilibrium at the scale / metal interface. In the laboratory setup used in this study, the $\mathrm{pO}_{2}$ is given by the $\mathrm{H}_{2}-\mathrm{H}_{2} \mathrm{O}$ equilibrium. According to Huin et al. [6] the relationship between the $\mathrm{H}_{2} \mathrm{O}$ partial pressure and Dew Point is given by Equations (1) and (2).

$$
\begin{array}{ll}
\log \mathrm{pH}_{2} \mathrm{O}=\frac{9.80 D P}{273+D P}-2.22 & \text { if } \mathrm{DP} \leq 0^{\circ} \mathrm{C} \\
\log \mathrm{pH}_{2} \mathrm{O}=\frac{7.58 D P}{240+D P}-2.22 & \text { if } \mathrm{DP}>0^{\circ} \mathrm{C}
\end{array}
$$

The partial pressure of oxygen $\left(\mathrm{pO}_{2}\right)$ in the furnace atmosphere, in atm, at the temperature $(T)$, in $\mathrm{K}$, is given by the Equation below [6]. In this Equation, $\mathrm{pH}_{2}$ denotes the partial pressure of hydrogen. The atmosphere considered in this study 
consists of $95 \%$ nitrogen and $5 \%$ hydrogen, their total pressure is 1 atm, thus, the $\mathrm{pH}_{2}=0.05$ atm and the $\mathrm{pH}_{2} \mathrm{O}$ was obtained by Eq. 1 .

$$
\frac{1}{2} \log p \mathrm{O}_{2}=3.00+\frac{13088}{T}+\log \left(\frac{p \mathrm{H}_{2} \mathrm{O}}{p \mathrm{H}_{2}}\right)
$$

For $\mathrm{Fe}-0.2 \% \mathrm{Si}$ alloy after 26 hours in isothermal conditions at $600^{\circ} \mathrm{C}$, TGA results showed a stable decarburization of the steel recorded in $\Delta \mathrm{m} / \mathrm{S}\left(\mathrm{mg} / \mathrm{cm}^{2}\right)$, see Fig. 1 . These results were also confirmed by Fig. 2, which presents GDOES analysis for the same sample. Through comparisons between carbon concentration profiles before (blue line) and after (red line) the selective oxidation test, it can be observed a strong decarburization after that test $(>120 \mu \mathrm{m}$ in depth).Similar to the present study, Liu et al. [7] found a ferrite layer (decarburization depth) of about $20 \mu \mathrm{m}$ depth.

Moreover, a small mass gain linked to oxide formation was also observed. These oxides were mainly formed along the grain boundaries and will be analyzed separately for each iron-based model alloy.

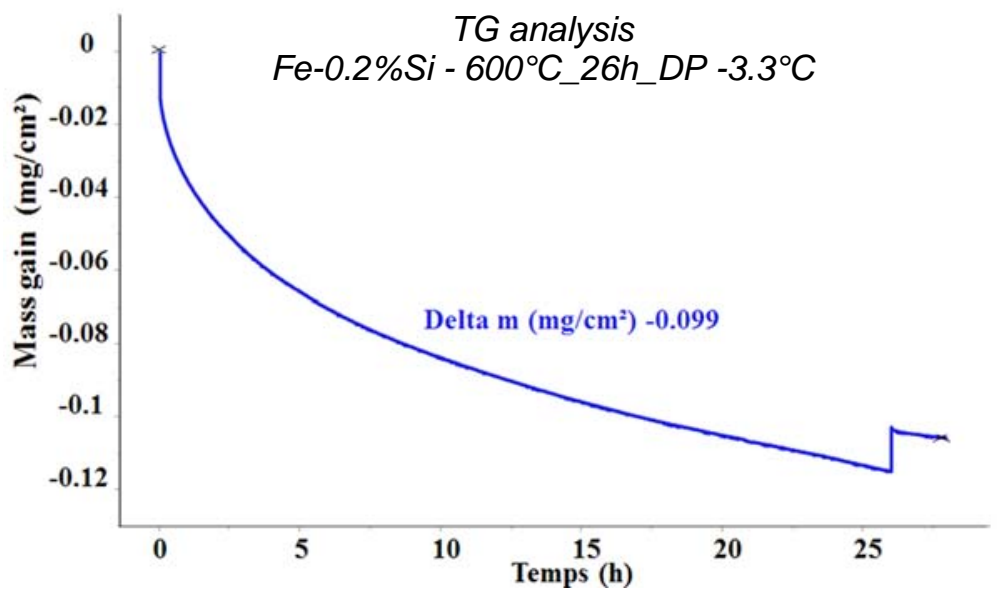

Figure 1. In-situ thermogravimetry signal during selective oxidation test of Fe- $0.2 \%$ Si alloy at $600^{\circ} \mathrm{C}$ for 26 hours in isotherm conditions $\left(\mathrm{N}_{2}-5 \% \mathrm{H}_{2}\right.$ atmosphere with $150 \mathrm{ml} / \mathrm{min}$ of total gas flow and Dew Point of $\left.-3.3^{\circ} \mathrm{C}\right)$.

Carbon Concentration Profiles:

$\mathrm{Fe}-0.2 \% \mathrm{Si}-600^{\circ} \mathrm{C} \_26 \mathrm{~h} \_\mathrm{DP}-3.3^{\circ} \mathrm{C}$

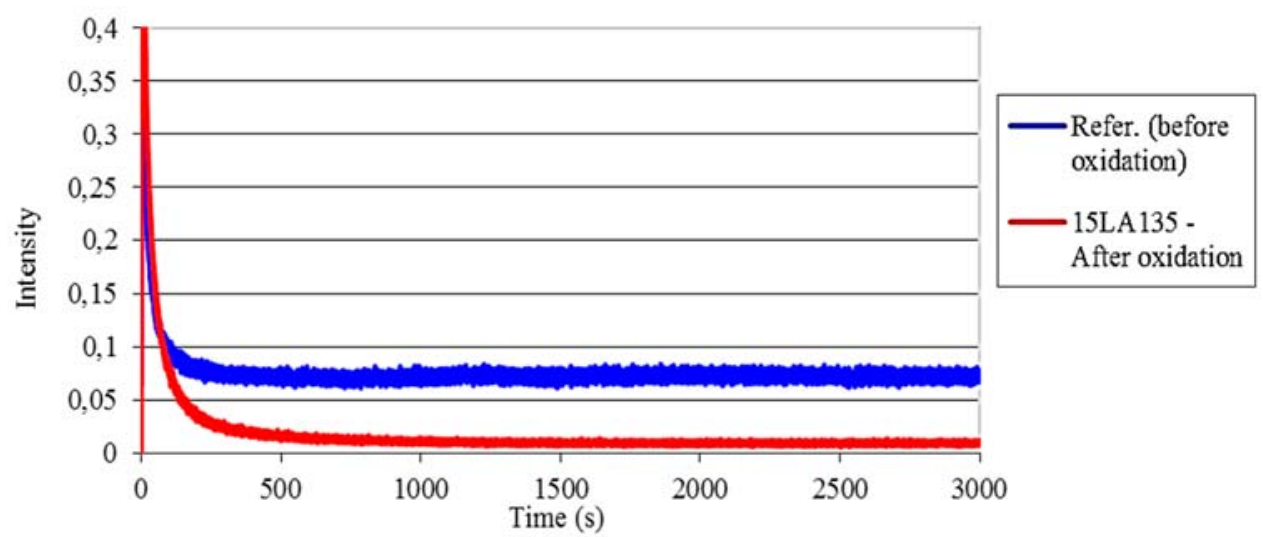

Figure 2. GDOES comparison results of Fe-0.2\%Si alloy before selective oxidation test (blue line) and after (red line). The carbon concentration profiles showed strong decarburization after test $(>120 \mu \mathrm{m}$ in GDOES analysis time of $3000 \mathrm{~s})$. 


\section{$3.2 \mathrm{Fe}-\mathrm{x} \% \mathrm{Si}$}

After selective oxidation trials, the cross sectional samples of Fe-x\%Si were analyzed by SEM and grain boundary oxidation lengths were measured. These tests were realized at different temperatures $\left(530^{\circ} \mathrm{C}, 600^{\circ} \mathrm{C}\right.$ and $\left.700^{\circ} \mathrm{C}\right)$ and for each temperature were studied for several durations (2, 6, 16 and 26 hours). The results indicated that GB oxidation lengths increase with increasing temperature and test duration for a given binary alloy.

The Fig. 3 showed SEM images comparison of $\mathrm{Fe}-0.2 \% \mathrm{Si}, \mathrm{Fe}-0.5 \% \mathrm{Si}$ and $\mathrm{Fe}-1.5 \% \mathrm{Si}$ in the same test conditions (at $600^{\circ} \mathrm{C}$ for 26 hours in $\mathrm{N}_{2}-5 \% \mathrm{H}_{2}$ atmosphere with 150 $\mathrm{ml} / \mathrm{min}$ of total gas flow and Dew Point of $-3.3^{\circ} \mathrm{C}$ ). These results revealed a decrease of grain boundary oxidation length with increasing Silicon content. In the case of Fe$0.2 \% \mathrm{Si}, \mathrm{Fe}-0.5 \% \mathrm{Si}$ was observed only grain boundary oxidation. However, for Fe$1.5 \%$ Si was verified grain boundary oxidation as well as bulk internal oxidation.
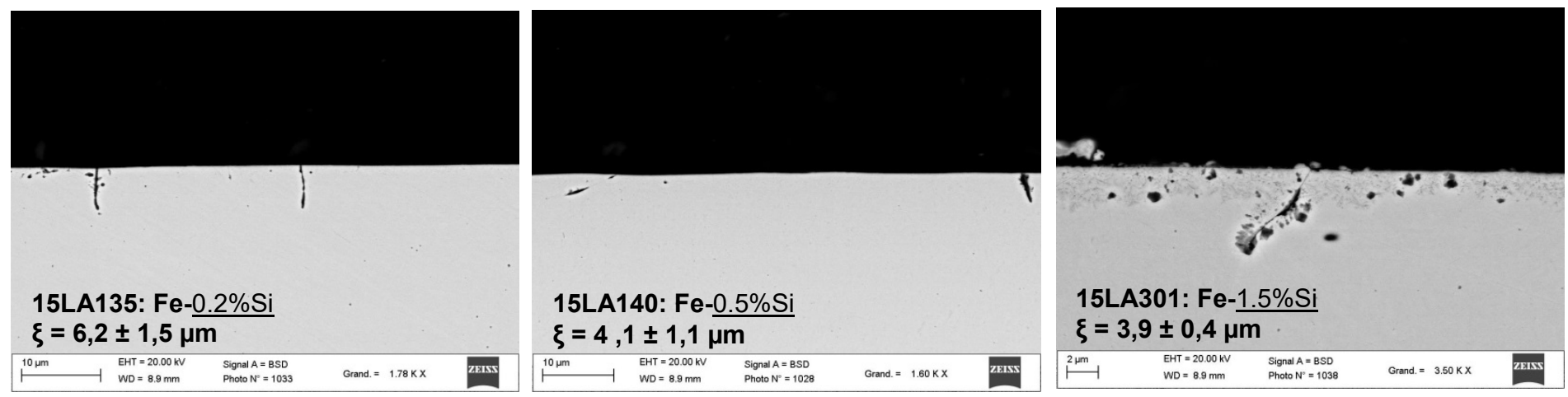

Figure 3. SEM images of cross sectional (a) Fe- $0.2 \% \mathrm{Si}$, (b) Fe- $0.5 \% \mathrm{Si}$ and (c) $\mathrm{Fe}-1.5 \% \mathrm{Si}$, after selective oxidation test at $600^{\circ} \mathrm{C}$ for 26 hours in $\mathrm{N}_{2}-5 \% \mathrm{H}_{2}$ atmosphere with $150 \mathrm{ml} / \mathrm{min}$ of total gas flow and Dew Point $-3.3^{\circ} \mathrm{C}\left(\mathrm{pO}_{2}=8.56 \times 10-27 \mathrm{~atm}\right)$.

SIMS analysis of the Fe- $0.2 \% \mathrm{Si}$ alloy after test at $600^{\circ} \mathrm{C}, 6 \mathrm{~h}$, DP $-3.3^{\circ} \mathrm{C}$ (Fig. 4) showed no Silicon diffusion toward surface. Thereby, during selective oxidation experiments there was a pure oxygen grain boundary diffusion phenomenon in the perpendicular direction to the surface. Silicon atomic content (yellow signal) remained constant, demonstrating that, there was not Silicon diffusion toward surface (coming from the bulk). For this sample the grain boundary oxidation length measured was $\xi=2.1 \pm 0.4 \mu \mathrm{m}$, this measurement can be also analyzed by SIMS mapping surface at different depths (Fig.4-b), that clearly evidence Silicon oxides in grain boundary. 


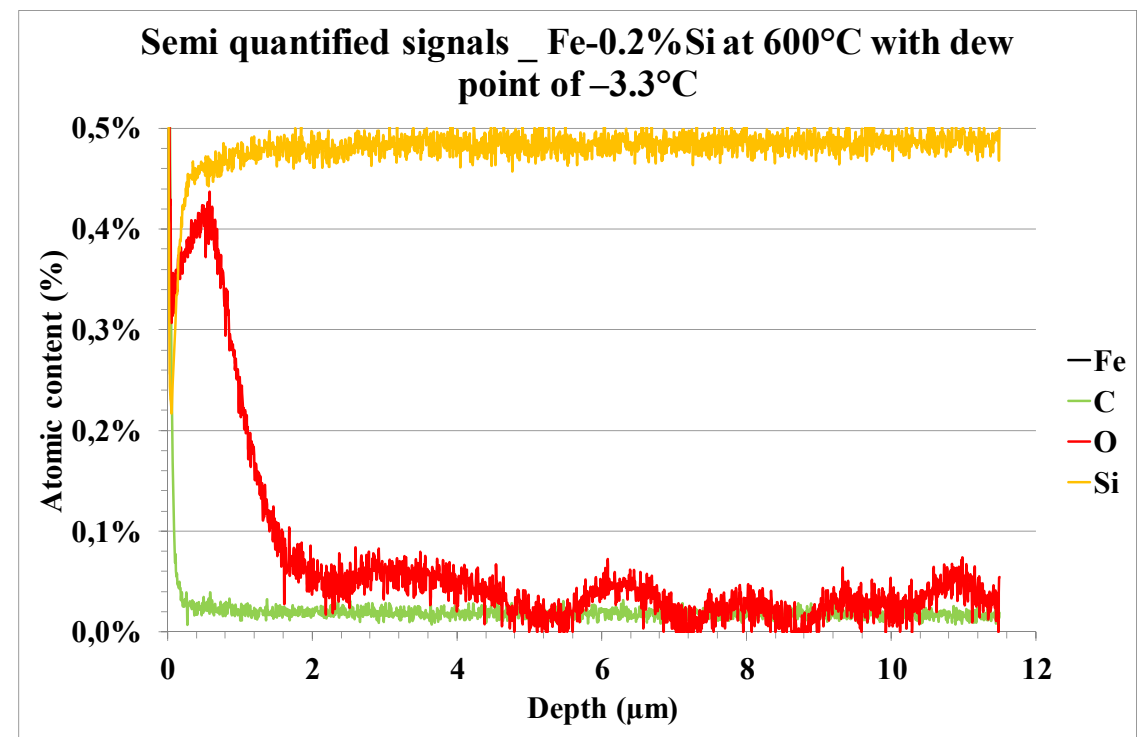

(a)

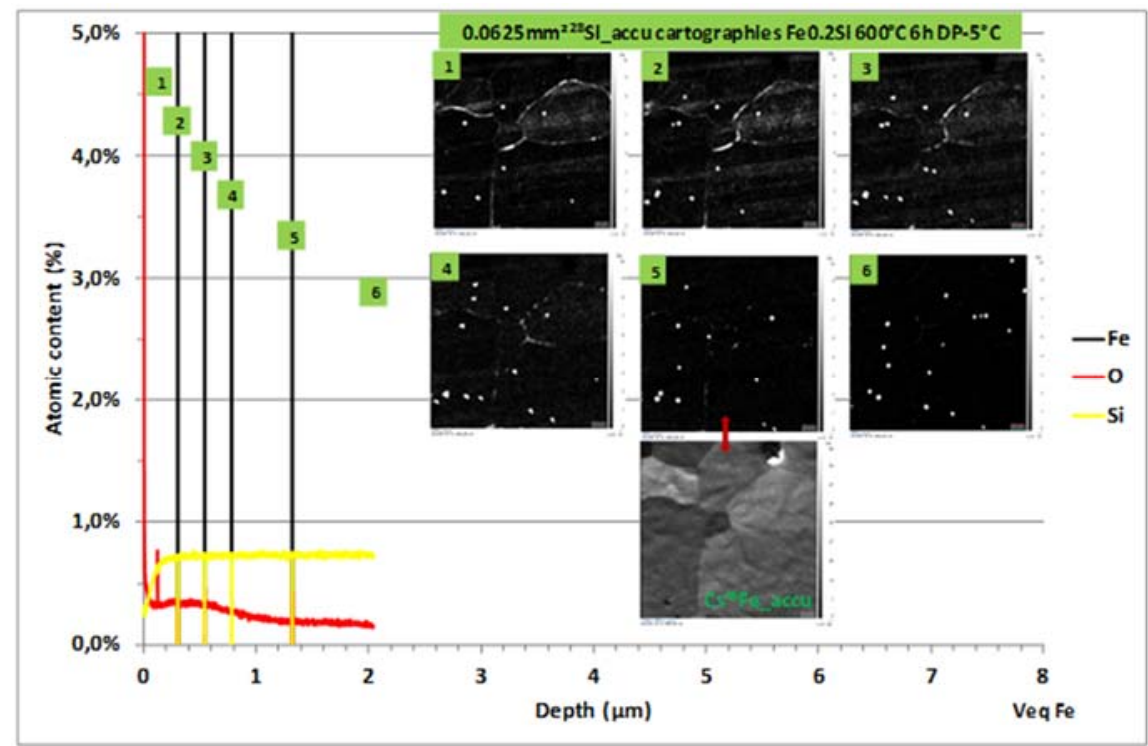

(b)

Figure 4. SIMS results in Fe- $0.2 \% \mathrm{Si}$ at $600^{\circ} \mathrm{C}$ with dew point of $-3.3^{\circ} \mathrm{C}$. (a) Semi quantified signals of Silicon and Oxygen. (b) Surface mapping with images $(250 \mu \mathrm{m} \times 250 \mu \mathrm{m})$ at different depth (black and white scale in Silicon, i.e. bright areas are Si-rich)

As far as we consider the lateral resolution of SIMS is sufficient to detect silicon concentration gradient around the grain boundary oxidation zones, the SIMS results lead to consider that there is no silicon diffusion from the grains.

In the frame of this hypothesis, for $\mathrm{Fe}-0.2 \% \mathrm{Si}$ and $\mathrm{Fe}-0.5 \% \mathrm{Si}$ the results can be interpreted by Harrisons classification in type $C$ regime diffusion [8] and also through Wagner's model [5] of the diffusion within the grain boundary. According to Wagner's theory, grain boundary oxidation length square $\left(\xi^{2}\right)$ is proportional to time, as expressed by Eq. 4:

$$
D o_{G B}=\frac{\xi^{2}}{t} \frac{v N_{i}^{c}}{2 N_{o}^{s}}
$$


In Eq. 4 , $\xi$ is the length of internal oxidation in grain boundary that was obtained from SEM images. $N_{o}^{s}$ is the oxygen molar fraction at the grain boundary surface [9], $D o_{G B}$ is the diffusion coefficient of oxygen in grain boundary, $\mathbf{t}$ the time spent in isotherm temperature , $\boldsymbol{v}$ the stoichiometric coefficient of the oxide (equal to 2 for $\mathrm{SiO}_{2}$ ) and $N_{i}^{c}$ the molar fraction of $i$ species in the steel.

Therefore, for each temperature the grain boundary oxygen diffusion coefficient "Do ${ }_{G B}$ " was determined using the value of slope $\left(\xi^{2} / \mathrm{t}\right)$. The graphic presented in Fig. 5 is an example of $\mathrm{Do}_{G B}$ determination for $\mathrm{Fe}-0.2 \% \mathrm{Si}$ at $600^{\circ} \mathrm{C}$ in $\mathrm{N}_{2}-5 \% \mathrm{H}_{2}$ atmosphere with $150 \mathrm{ml} / \mathrm{min}$ of total gas flow and Dew Point of $-3.3^{\circ} \mathrm{C}\left(\mathrm{pO}_{2}=8.56 \times 10^{-27} \mathrm{~atm}\right)$.

The grain boundary oxidation length squared uncertainties $\left(\Delta \xi^{2}\right)$ were calculated with a confidence interval of $95 \%$ from the experimental results discrepancy. The minimum and maximum values of the linear regression slope were determined graphically from the $\Delta \xi^{2}$ values. These extreme slope values aim to calculate the slope uncertainty $(\Delta s)$. Then, from $\Delta s$, it is possible to find the uncertainty of the diffusion coefficient of oxygen in grain boundary $\left(\Delta \mathrm{Do}_{G B}\right)$ from the differential of the slope (Eq. 5):

$$
\frac{\Delta D o_{G B}}{D o_{G B}}=\frac{\Delta s}{s}
$$

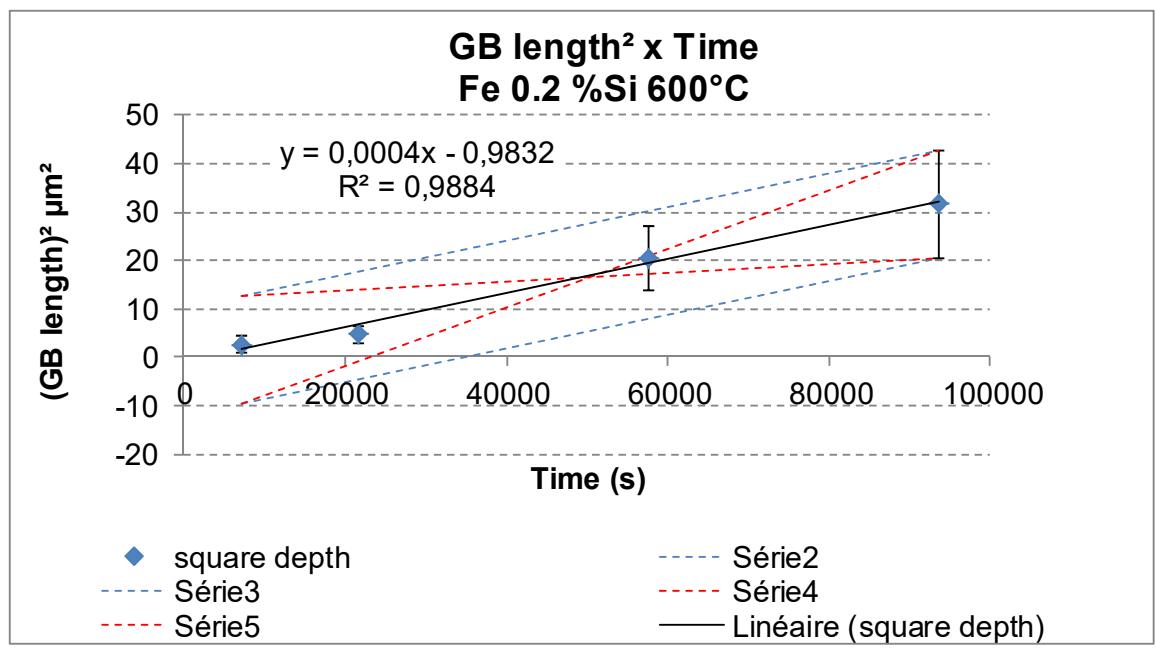

Figure 5. Grain boundary oxidation length squared as a function of isothermal duration in $\mathrm{Fe}-0.2 \% \mathrm{Si}$ at $600^{\circ} \mathrm{C}$ with dew point of $-3.3^{\circ} \mathrm{C}$.

Table 2 gives the data used to calculate $\mathrm{Do}_{G B}=43 \pm 32 \mu \mathrm{m}^{2} / \mathrm{s}$ at $600^{\circ} \mathrm{C}$. The bulk oxygen diffusion coefficient at $600^{\circ} \mathrm{C}$ is $0.75 \mathrm{\mu m}^{2} / \mathrm{s}$ [6], thus, it can therefore be concluded that grain boundary diffusion is about 60 times faster than bulk diffusion.

Table 2. Data used in calculation of grain boundary oxygen diffusion coefficient (DoGB) for Fe-0.2\%Si at $600^{\circ} \mathrm{C}$

\begin{tabular}{|c|c|c|c|c|c|}
\hline \multicolumn{6}{|c|}{ DoGв calculation data: $\mathrm{Fe}-0.2 \% \mathrm{Si} \_600^{\circ} \mathrm{C} \_\mathrm{DP}-3.3^{\circ} \mathrm{C}$} \\
\hline Slope $\left(\mu m^{2} / s\right)$ & $N_{i}^{c}$ & $N_{o}^{s}$ & $\boldsymbol{v}$ & $\operatorname{DogB}_{\left(\mu m^{2} / s\right)}$ & $\Delta \operatorname{DogB}_{\mathrm{GB}}\left(\mu m^{2} / \mathrm{s}\right)$ \\
\hline 0.00035 & 0.004 & $3.24 \mathrm{E}-08$ & 2 & 43 & \pm 32 \\
\hline
\end{tabular}

The same procedure was applied to obtain oxygen grain boundary diffusion coefficient $\mathrm{Do}_{G B}\left(\mu \mathrm{m}^{2} / \mathrm{s}\right)$ in $\mathrm{Fe}-0.5 \% \mathrm{Si}$ at $600^{\circ} \mathrm{C}$. Therefore in this case Do $G B$ is equal to $55 \pm 33 \mu \mathrm{m}^{2} / \mathrm{s}$, being about 74 times faster than bulk diffusion. 


\subsection{Fe-y\%Mn}

Cross sectional of $\mathrm{Fe}-2 \% \mathrm{Mn}$ and $\mathrm{Fe}-5 \% \mathrm{Mn}$ were analyzed by SEM / EDS and grain boundary oxidation lengths were measured. In the same selective oxidation tests conditions (at $600^{\circ} \mathrm{C}$ for $26 \mathrm{~h}$ and dew point $-3.3^{\circ} \mathrm{C}$ ), the SEM images in Fig. 6 revealed that increasing Manganese content there was a decrease of grain boundary oxidation length, as well as observed for Fe-x\%Si binary alloys.
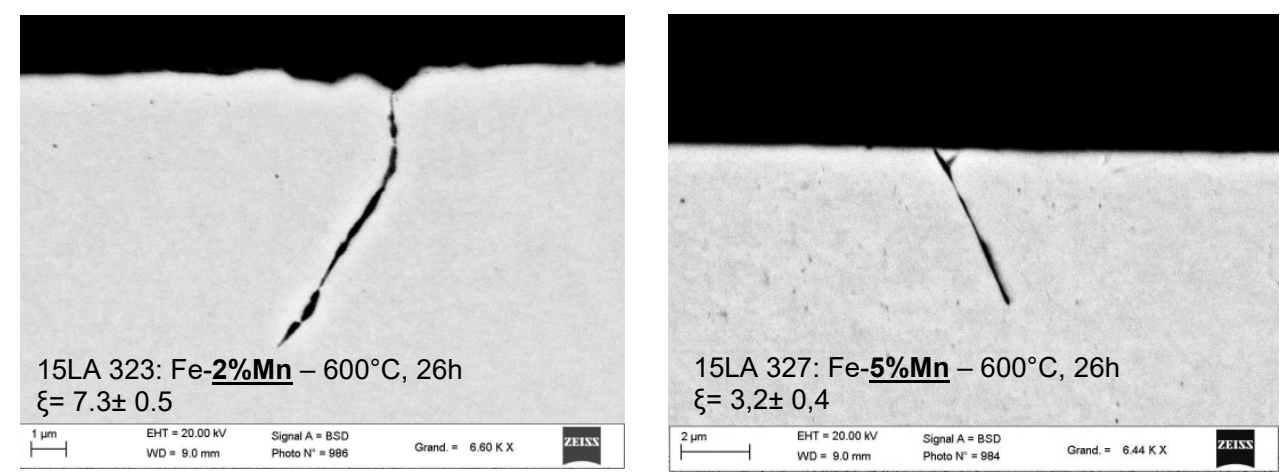

Figure 6. SEM images of cross sectional (a) Fe-2\%Mn, (b) Fe-5\%Mn, after selective oxidation test at $600^{\circ} \mathrm{C}$ for 26 hours in $\mathrm{N}_{2}-5 \% \mathrm{H}_{2}$ atmosphere with $150 \mathrm{ml} / \mathrm{min}$ of total gas flow and Dew Point $-3.3^{\circ} \mathrm{C}$ $\left(\mathrm{pO}_{2}=8.56 \times 10^{-27} \mathrm{~atm}\right)$.

The study for different time and temperature of isothermal cycle for Fe-y\%Mn showed results similar to those found for $\mathrm{Fe}-\mathrm{x} \% \mathrm{Si}$, that is, the grain boundary oxidation length measured increases with increasing of the isothermal temperature and tests durations.

The EDS results for oxidation selective test in $\mathrm{Fe}-5 \% \mathrm{Mn}$ at $600^{\circ} \mathrm{C}$ for $26 \mathrm{~h}$ and dew point $-3.3^{\circ} \mathrm{C}$ (Fig. 7), showed strong enrichment of Manganese and Oxygen in the grain boundary and Manganese depletion zone around the grain boundary. Therefore, with qualitative analysis presented by EDS, internal oxidation is not only controlled by oxygen diffusion and the Eq. 4 cannot be applied. In this case, it becomes necessary to quantify the manganese depletion in the vicinity of the oxidized zones, and this will be done in the near future.
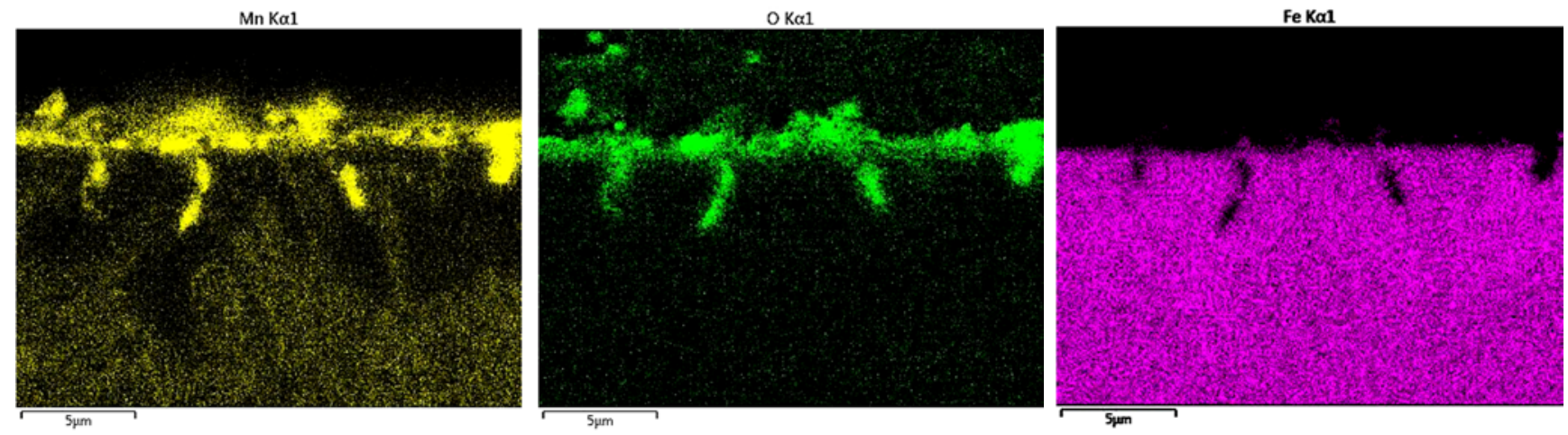

Figure 7. EDS results of Fe-5\%Mn, after selective oxidation test at $600^{\circ} \mathrm{C}$ for 26 hours in $\mathrm{N} 2-5 \% \mathrm{H} 2$ atmosphere with $150 \mathrm{ml} / \mathrm{min}$ of total gas flow and Dew Point $-3.3^{\circ} \mathrm{C}$. The grain boundary oxidation length was $3.2 \pm 0.4 \mu \mathrm{m}$. 


\subsection{Fe-x\%Si-y\%Mn}

Through comparisons between SEM images and grain boundary length measurement for binary and ternary model alloys, it can be perceived that, when the elements Silicon and Manganese are present together, the grain boundary oxidation length is deeper and thinner.

Auinger et al. [2] studied grain boundary oxidation in binary and ternary iron-based model alloys $\mathrm{Fe}-\{\mathrm{Al}, \mathrm{Cr}, \mathrm{Mn}, \mathrm{Si}\}$ by ${ }^{18} \mathrm{O}$-isotope signal. They showed with ToF-SIMS results, clear signs of fast oxygen diffusion along the grain boundary in all manganese containing alloys. Thus, predominant grain boundaries oxidation could only be observed in the case of manganese alloys (i.e. Fe-1\%Si-2\%Mn), suggesting a significant influence of this element.

Fig. 9 shows the EDS results for selective oxidation experiment in $\mathrm{Fe}-0.4 \% \mathrm{Si}-1 \% \mathrm{Mn}$ at $700^{\circ} \mathrm{C}$ for $12 \mathrm{~h}$ and dew point $-3.3^{\circ} \mathrm{C}$, for this sample the grain boundary oxidation length is $\xi=24.7 \pm 2.5 \mu \mathrm{m}$. There was segregation of Oxygen, Silicon and Manganese along the grain boundary. However, only where Manganese is, it can be observed the depletion zone around grain boundary.
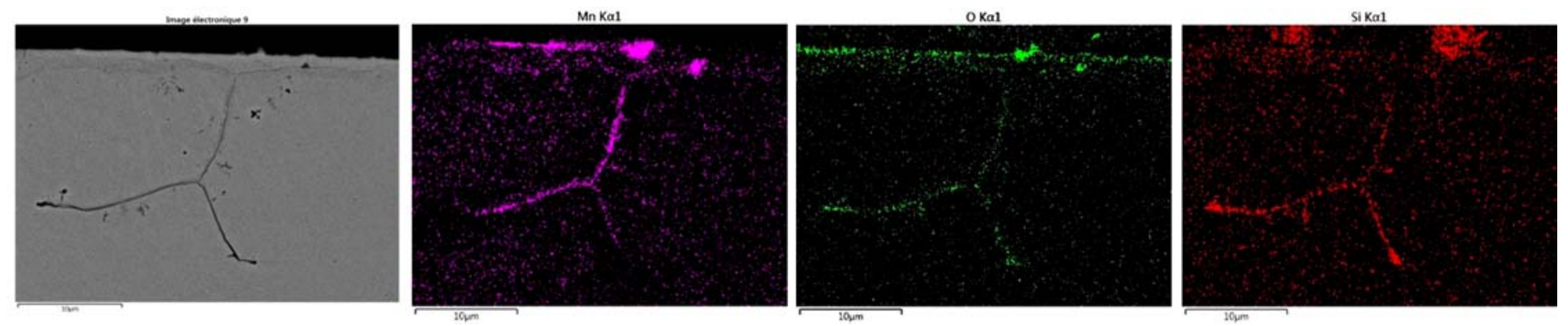

Figure 9. EDS results of Fe- $0.4 \% \mathrm{Si}-1 \% \mathrm{Mn}$, after selective oxidation test at $700^{\circ} \mathrm{C}$ for $12 \mathrm{~h}$ and dew point $-3.3^{\circ} \mathrm{C}$ in $\mathrm{N} 2-5 \% \mathrm{H} 2$ atmosphere with $150 \mathrm{ml} / \mathrm{min}$ of total gas flow and Dew Point $-3.3^{\circ} \mathrm{C}$. The grain boundary oxidation length was $\xi=24.7 \pm 2.5 \mu \mathrm{m}$.

\section{CONCLUSION}

The present work was aimed at investigating the development of grain boundary oxidation for different coiling temperatures in binary and ternay iron-based model alloys. The knowledge acquired from this study will help to understand grain boundary oxidation in new steels with complex alloy compositions.

SEM images and grain boundary oxidation measurement of Fe-x\%Si and $\mathrm{Fe}-\mathrm{y} \% \mathrm{Mn}$ showed a decrease of grain boundary oxidation depth with increasing Silicon or Manganese content. Moreover, Fe-x\%Si-y\%Mn iron-based model alloy showed significantly grain boundary oxidation length when compared with binary iron-based model alloys (where Si and Mn elements are present separately).

GDOES analysis of carbon concentration profiles and TGA results revealed a stable decarburization of the steel during selective oxidation experiments.

SIMS analysis in $\mathrm{Fe}-0.2 \% \mathrm{Si}$ indicated that there was no Silicon diffusion in the perpendicular direction to the surface (coming from the bulk); there was only oxygen grain boundary diffusion through the surface.

Based on this assumption, the Wagner's theory application allows to determine the Oxygen grain boundary diffusion coefficient "Do ${ }_{G B}$ " which is almost 60 to 70 times faster than Oxygen bulk diffusion coefficient for $\mathrm{Fe}-0.2 \% \mathrm{Si}$ and $\mathrm{Fe}-0.5 \% \mathrm{Si}$ alloys. This analysis cannot be applied for Fe-y\%Mn because during the selective oxidation 
experiments there was Oxygen and Manganese diffusion in the perpendicular direction to the surface.

The next step of this work is to better characterize the silicon and manganese composition distribution around the oxidized grain boundaries, using nanoSIMS or Auger analysis to obtain a better lateral resolution than the one obtained by SIMS or EDS. In the case of $\mathrm{Fe}-\mathrm{x} \% \mathrm{Si}$ alloys, the goal is to confirm that there is no mobility of silicon and that the assumption admitted in the presente contribution is valid. For the $\mathrm{Fe}-\mathrm{y} \% \mathrm{Mn}$ alloys, the objective is to quantify the manganese gradient in order to obtain, in-fine, values for the oxygen grain boundary diffusion coefficient in such binary alloys.

\section{Acknowledgments}

The authors wish to express their thanks to ArcelorMittal Global Research and Development Maizières, University of Technology of Compiègne and to Association Nationale de la Recherche et de la Technologie (ANRT) for the financial support. They also would like to thank Mr. Sebastien Crèmel and Mrs. Valerie Philippe for their assistance and discussions with SIMS measurements. Thanks to Technical team of process engineering department for the support with ATG and Mr. Jean Michel Mataigne and Mr. Didier Huin for scientific discussions.

\section{REFERENCES}

1 Bellhouse EM, Mertens AIM, Mcdermid JR. Development of the surface structure of TRIP steels prior to hot-dip galvanizing. Materials Science \& Engineering A. 2007; 463: 147-156.

2 Auinger M, Praig GV, Linder B, Danninger H. Grain Boundary Oxidation in Iron-Based Alloys, investigated by 180 enriched Water Vapour - The Effect of Mixed Oxides in binary and ternary Fe-\{Al, Cr,Mn, Si\} Systems. Corrosion Science. 2015; 96:133-143.

3 Williams PL, Mishin Y. Thermodinamics of grain boundary premelting in alloys. II. Atomistic Simulation. Acta Materialia. 2009; 57: 3786-3794.

4 Huin D. Evaluation au moyen du modèle DIFFANI de l'effet de la température de bobinage des coils sur les phénomènes ultérieurs d'oxydation sélective. 2011; ArcelorMittal Global R\&D Report No. PE/03/N/163: 1-8.

5 Wagner C. Reaktionstypen bei der Oxydation von Legierungen. Zeitschrift für Elektrochemie. 1959; 63: 772-782.

6 Huin D, Flauder P, Leblond JB. Numerical simulation of internal oxidation of steels during annealing treatments. Oxidation of Metals. 2005; 64: 131-167.

7 Liu H, He Y, Swaminathan S, Rohwerder M, Li L. Effect of dew point on the surface selective oxidation and subsurface microstructure of TRIP-aided steel. Surface \& Coatings Technology. 2011; 206: 1237-1243.

8 Harrison LG. Influence of dislocations on diffusion kinetics in solids with particular reference to the alkali halides. Trans. Faraday Soc. 1961; 57: 1191.

9 Mataigne JM., Lamberigts M, Leroy V. Selective oxidation of cold-rolled steel during recrystalization annealing. The Minerals, Metals \& Materials Society, 1992; 511-528. 